\title{
Higher maternal parathyroid hormone concentration at delivery is not associated with smaller newborn size
}

\author{
Huma Qamar(101,2, Nandita Perumal ${ }^{1,3}$, Eszter Papp ${ }^{1}$, Alison D Gernand ${ }^{4}$, Abdullah AI Mahmud ${ }^{5}$ and Daniel E Roth ${ }^{1,2,6}$ \\ ${ }^{1}$ Centre for Global Child Health, Hospital for Sick Children, Toronto, Ontario, Canada \\ 2Department of Nutritional Sciences, University of Toronto, Toronto, Ontario, Canada \\ ${ }^{3}$ Department of Epidemiology, Dalla Lana School of Public Health, University of Toronto, Toronto, Ontario, Canada \\ ${ }^{4}$ Department of Nutritional Sciences, Pennsylvania State University, University Park, Pennsylvania, USA \\ ${ }^{5}$ Nutrition and Clinical Services Division, International Centre for Diarrhoeal Disease Research (icddr,b), Dhaka, Bangladesh \\ ${ }^{6}$ Department of Paediatrics, Hospital for Sick Children and University of Toronto, Toronto, Ontario, Canada
}

Correspondence should be addressed to D E Roth: daniel.roth@sickkids.ca

\begin{abstract}
Intrauterine growth restriction (IUGR) reflects inadequate growth in-utero and is prevalent in low resource settings. This study aimed to assess the association of maternal delivery parathyroid hormone (PTH) - a regulator of bone turnover and calcium homeostasis - with newborn anthropometry, to identify regulators of PTH, and to delineate pathways by which maternal PTH regulates birth size using path analysis. This was a cross-sectional analysis of data from participants $(n=537)$ enrolled in the Maternal Vitamin D for Infant Growth trial in Dhaka, Bangladesh. Primary exposures were maternal delivery intact PTH (iPTH) or whole PTH (WPTH) and outcomes were gestational age- and sex-standardized z-scores for birth length (LAZ), weight (WAZ), and head circumference (HCAZ). Hypothesized regulators of PTH included calcium and protein intake, vitamin $D$, magnesium, fibroblast-like growth factor-23 (FGF23), and C-reactive protein. Maternal iPTH was not associated with birth size in linear regression analyses; however, in path analysis models, every SD increase in $\log (\mathrm{iPTH})$ was associated with 0.08SD (95\% Cl: 0.002, 0.162) higher LAZ. In linear regression and path analysis models, WPTH was positively associated with WAZ. Vitamin D suppressed PTH, while FGF23 was positively associated with PTH. In path analysis models, higher magnesium was negatively associated with LAZ; FGF23 was positively associated and protein intake was negatively associated with LAZ, WAZ, and HCAZ. Higher maternal PTH in late pregnancy is unlikely to contribute to IUGR. Future studies should investigate maternal FGF23, magnesium and protein intake as regulators of fetal growth, particularly in settings where food insecurity and IUGR are public health problems.
\end{abstract}

\section{Key Words}

- parathyroid hormone

- pregnancy

- fetal growth

- intrauterine growth restriction

- vitamin D

- 25-hydroxyvitamin D

- FGF23

- small-for-gestational age

\section{Introduction}

Intrauterine growth restriction (IUGR), or inadequate fetal growth, is associated with short- and long-term adverse health outcomes (1, 2, 3, 4, 5). Low birthweight (LBW), defined as birthweight less than $2500 \mathrm{~g}$, and small-for-gestational age (SGA), defined as birthweight below the $10^{\text {th }}$ centile of gestational age- and sex-matched healthy reference population, are conventional indicators of IUGR. Length and head circumference at birth are important indicators of fetal skeletal growth and are correlated with indicators of IUGR $(6,7)$; for example, birth length strongly correlates with fetal femur length based on ultrasound (8). In low- and middle-income https://ec.bioscientifica.com

https://doi.org/10.1530/EC-21-0056 (c) 2021 The authors Published by Bioscientifica Ltd

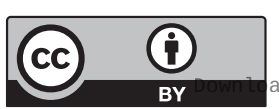

This work is licensed under a Creative Commons Attribution 4.0 International License. ded from Bioscientifica.com at 04/26/2023 07:15:27AM 
countries such as Bangladesh, where LBW and SGA are prevalent (9), reductions in both newborn weight and length are observed $(10,11)$.

Parathyroid hormone (PTH) is a peptide hormone that primarily regulates calcium homeostasis by binding to the PTH 1 Receptor (PTH1R) $(12,13)$, and is itself regulated by vitamin $\mathrm{D}$ and calcium in feedback loops. Chronic exposure of bones to PTH is generally observed to lead to decreases in bone mineral content (12). Evidence from in vivo and clinical studies suggests that parathyroid hormone does not cross the placenta $(14,15)$. As such, maternal PTH likely regulates bone growth through transplacental calcium flux or other indirect mechanisms.

During pregnancy, the increased demand for calcium to support fetal growth is met by increasing maternal intestinal absorption of calcium from the diet, reabsorption from the kidneys, and resorption of bone (16). In some women, plasma/serum PTH concentrations increase during pregnancy, which may help to mobilize calcium and promote fetal growth in settings of dietary calcium deficits or vitamin D deficiency $(15,17,18,19)$. However, in an American pregnancy cohort, Scholl et al. reported that PTH was negatively associated with birth length and head circumference (20). Furthermore, women with elevated PTH and either low maternal dietary calcium intake and/or vitamin D deficiency had a higher risk of SGA and lower birth length and head circumference (20). Studies in Ireland and Norway reported no association between PTH and SGA or birthweight (21); however, an Australian study reported a positive association between maternal PTH concentrations and knee-to-heel length (22). These inconsistent findings and the lack of evidence from low- and middle-income settings with a high prevalence of SGA/LBW warrant further investigation.

To understand the biological mechanisms by which PTH may be associated with fetal growth, regulators of PTH are important to consider. PTH synthesis and activity may be regulated by a limited set of nutritional and endocrine factors. The vitamin D metabolite 1,25-dihydroxyvitamin D directly regulates PTH in the parathyroid through negative feedback loops to suppress circulating concentrations $(23,24)$. Calcium is a direct suppressor of PTH through the calcium-sensing receptor (25). Fibroblast-like growth factor-23 (FGF23), a marker of bone metabolism, has also been postulated as a regulator of PTH secretion, although the direction of this effect is not yet well characterized (26, $27,28,29,30$ ). Additional factors that may regulate PTH include magnesium and systemic inflammation markers such as C-reactive protein (CRP) $(13,31,32,33)$. These factors may serve as points of intervention, for example, through modifying maternal dietary intake of vitamin D, calcium, or magnesium. However, the relationships between nutritional and endocrine regulators of $\mathrm{PTH}$, and their direct or indirect (i.e. PTH-mediated) associations with newborn size, have not been fully elucidated.

In a population with concurrent high prevalences of IUGR, vitamin D deficiency, and dietary calcium deficits, this study aimed to estimate the associations between maternal PTH concentrations and newborn size at birth, to identify potentially modifiable nutritional and endocrine factors associated with maternal PTH, and to assess the direct and indirect (i.e. PTH-mediated) pathways by which maternal PTH and its regulators may influence fetal growth. We hypothesized that PTH would be negatively associated with birth size due to a higher prevalence of calcium metabolic stress in this population. We also hypothesized that PTH would function as a mediator of the association of upstream regulators of PTH and birth size.

\section{Methods}

\section{Study design}

This was a cross-sectional analysis of data from a subset of participants enrolled in the Maternal Vitamin D for Infant Growth (MDIG) Trial in Dhaka, Bangladesh (Trial Registration Number: NCT01924013, clinicaltrials.gov). The MDIG trial was a double-blind, randomized placebocontrolled trial designed to estimate the dose-ranging effects of prenatal vitamin D supplementation (4200 IU/week, $16,800 \mathrm{IU} /$ week, and 28,000 IU/week) and postpartum supplementation $(28,000 \mathrm{IU} /$ week among half the women receiving 28,000 IU/week prenatally), vs placebo on infant length at 1 year of age. Participants enrolled in the MDIG trial were co-supplemented with daily calcium $(500 \mathrm{mg}$ ) and iron and folic acid (66 mg elemental iron, $350 \mu \mathrm{g}$ folic acid). Detailed descriptions of the methods and results of the trial are described elsewhere $(34,35)$. Approval for the MDIG trial and biochemical analyses related to the PTH axis was obtained from research ethics committees at the Hospital for Sick Children and the International Center for Diarrheal Disease Research, Bangladesh (icddr,b). Written informed consent was obtained from all participants for participation and storage of biological specimens.

\section{Study subjects}

Healthy pregnant women attending antenatal visits at the Maternal and Child Health Training Institute (MCHTI)

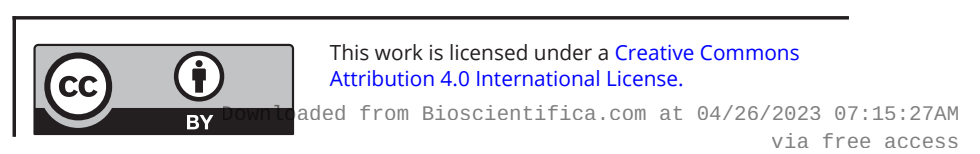


at least 18 years of age and at 17-24 completed weeks of gestation at the time of the visit (based on recalled last menstrual period and ultrasound performed by technicians at MCHTI) were invited to participate in the MDIG trial. Detailed inclusion and exclusion criteria are described elsewhere $(34,35)$.

A total of 537 mother-infant pairs were selected for this study (Supplementary Fig. 1, see section on supplementary materials given at the end of this article). Participants were selected from a subset of mother-infant pairs in MDIG selected for biochemical analysis based on availability of infant and/or cord blood samples. Additional inclusion criteria for the present study included maternal blood specimens collected at delivery and newborn anthropometry performed within $48 \mathrm{~h}$ of birth $(n=490)$. To increase the sample size to describe changes in PTH concentrations from mid-gestation to delivery in the absence of vitamin D supplementation, an additional 47 participants from the placebo group were also included in this study (Supplementary Fig. 1).

\section{Data collection}

\section{Clinical, sociodemographic and dietary data}

Baseline questionnaires at enrollment collected maternal age, gravidity, and socioeconomic status indicators. Questionnaires administered at the delivery visit provided information on sex of the newborn and season of birth. Gestational age at birth was derived using recorded date of birth and recalled last menstrual period and/or baseline ultrasound. A 41-item non-quantitative food frequency questionnaire (FFQ) was administered at baseline to estimate habitual maternal calcium and protein intake (Supplementary Method 1). Calcium intake was expressed in milligrams per day $(\mathrm{mg} /$ day) and protein intake was expressed in grams of protein per kilogram body weight per day $(\mathrm{g} / \mathrm{kg} /$ day $)$.

\section{Infant anthropometry}

Crown-to-heel length, rump-to-knee length (RKL), weight, and head circumference were measured independently by two study personnel within $48 \mathrm{~h}$ of birth, based on a predefined protocol (Supplementary Method 2). Length was initially measured using a length board with a counter display and ball bearing mounted sliding footboard (Harpenden infantometer; Holtain, Crymych, UK); however due to frequent decalibration, it was changed to a wooden length board
(Infant/Child ShorrBoard; Weigh and Measure, Olney, MD, USA). A total of 128 infants (24\%) were measured using the Harpenden length board and 402 infants (76\%) were measured using the Shorrboard.

Intergrowth-21st growth standards (36) were used to derive sex- and gestational age-adjusted z-scores for length (LAZ), weight (WAZ), and head circumference (HCAZ).

\section{Specimen collection and laboratory methods}

Maternal specimens were collected and stored using a standard protocol (Supplementary Method 3). Assay information and performance indicators for all lab analyses are recorded in Supplementary Table 1.

Maternal baseline and delivery plasma PTH concentrations were quantified using intact PTH (iPTH) and whole PTH (wPTH) sandwich ELISA kits (Immutopics 60-3100 and 60-3000, respectively, Athens, OH, USA). The iPTH assay measures concentrations of the whole 84 amino acid PTH peptide and long fragments that are missing the first few amino acids from the $\mathrm{n}$-terminus because the epitope for the detection antibody is located in the middle of the peptide. The wPTH assay uses a detection antibody targeting the first four amino acids of the PTH protein, and therefore measures only the whole (bioactive) PTH peptide without any inactive fragments. Although $\mathrm{wPTH}$ may provide a more physiologically relevant measure of the active PTH peptide, we also present analyses using iPTH to compare to prior studies of the association of maternal PTH and birth size, all of which used iPTH assays $(20,21,22,37)$.

Maternal serum 25-hydroxyvitamin D $(25(\mathrm{OH}) \mathrm{D})$ concentrations were measured using high-performance liquid chromatography-tandem mass spectrometry (LC-MS/MS) following methodology previously described (38). Maternal plasma FGF23 was measured using a second-generation c-terminal FGF23 ELISA. Maternal plasma CRP was measured using a sandwich ELISA and maternal serum magnesium was measured using a quantitative colorimetric assay.

If any biomarker analyses yielded unquantifiable values due to concentrations being below the standard curve detection limit, half the lowest standard of the assay was imputed for analysis (Supplementary Table 1). Values above the upper limit of detection were imputed as the highest standard curve concentration. For CRP, values that were above the upper limit of detection were imputed extrapolating from the standard curve (Supplementary Table 1).

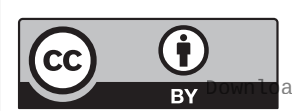

This work is licensed under a Creative Commons Attribution 4.0 International License. ded from Bioscientifica.com at 04/26/2023 07:15:27AM 


\section{Data analysis}

Participant characteristics and biomarker concentrations were expressed as mean \pm s.D., median (25th percentile, 75 th percentile), or frequencies and percentages. Maternal PTH, FGF23, CRP, and 25(OH)D were log-transformed due to right-skewing of the data. Participant characteristics were compared between women with baseline iPTH concentrations (17-24 weeks' gestation) that were above or below the 80th percentile of the iPTH distribution (5.81 pmol/L). Similar to Hemmingway et al. (21), we used the 80th percentile of the distribution to define elevated iPTH, as there is no established reference ranges for PTH in pregnancy. Among women randomized to the placebo group, we reported baseline and delivery iPTH and wPTH concentrations, stratified by $25(\mathrm{OH}) \mathrm{D}$ status $(<30 \mathrm{nmol} / \mathrm{L}$; 30-50 nmol/L; $\geq 50 \mathrm{nmol} / \mathrm{L}$ ) and/or calcium intake (above/below the 50th percentile of intake).

To estimate the associations of maternal delivery PTH (iPTH and wPTH) with birth LAZ, WAZ, and HCAZ, we used unadjusted and multivariable-adjusted linear regression models. A modified Poisson regression with robust error variance (39) was used to estimate the association of delivery PTH with the risk of being SGA. Potential confounders selected a priori for inclusion in multivariable regression models included magnesium, FGF23, CRP, vitamin D treatment group, maternal age, maternal height, maternal education, asset index (derived from participant ownership of various items (34)), gravidity, gestational age at birth, season of birth, and protein intake. Pre-pregnancy maternal weight/BMI were not available to be included in the multivariable model; however, in sensitivity analyses, we found that including postpartum BMI did not change inferences (data not shown). Models, where RKL was the outcome, were additionally adjusted for sex. Although vitamin D did not significantly affect any newborn size parameters in the main trial analyses (34), vitamin D group was included in all models. All effect estimates were scaled to a 90\% increase in $\mathrm{iPTH}$ and a 73\% increase in wPTH concentrations to reflect a large but biologically plausible difference in PTH concentrations, which corresponds to the observed difference in delivery PTH between the highest-dose vitamin D intervention (28,000 IU/week) and the placebo group in the MDIG cohort (34). Sensitivity and subgroup analyses were conducted to assess the robustness of our findings (Supplementary Method 4).

To identify regulators of PTH, delivery iPTH and wPTH concentrations were each regressed on vitamin D treatment group, magnesium, FGF23, CRP, protein intake, and calcium intake in separate linear regression models. Multivariable models included all proposed regulators of PTH, maternal age, maternal education, asset index and gravidity. In sensitivity analyses, vitamin $\mathrm{D}$ treatment group was substituted with $25(\mathrm{OH}) \mathrm{D}$ concentrations in multivariable models, and analyses were limited to women randomized to receive placebo $(n=142)$.

To test an integrated biological model of the direct and indirect pathways by which delivery PTH and its regulators are associated with birth LAZ, WAZ, and HCAZ, path analysis was used as a method to simultaneously perform mediation analyses (Supplementary Method 5). From the path analysis model, we present direct, indirect (mediated) and total effects, which represented both associations and causal effects (when vitamin D supplementation was the predictor). Maternal calcium intake and delivery CRP concentrations were not included in the final path model as they did not explain a meaningful level of variance in delivery PTH and birth size, and did not improve model fit.

All results were presented as point estimates of the effect size, with 95\% CIs and P-values. We considered $P$-values less than 0.05 as statistically significant. Data were analyzed with Stata version 15.1 (StataCorp 2017).

\section{Results}

\section{Maternal and infant characteristics}

Participant characteristic and biomarker data, stratified by baseline iPTH concentration (measured at 17-24 weeks of gestation), are summarized in Table 1 . With the exception of $25(\mathrm{OH}) \mathrm{D}$ concentrations at baseline, delivery iPTH and wPTH, participant characteristics did not differ by baseline iPTH. Participants selected for this sub-study were generally not different compared to the rest of the MDIG cohort; however, a higher proportion of women in this substudy gave birth by cesarean section, which is likely due to a higher proportion of hospital births in our subsample (Supplementary Table 2). Median iPTH concentration at delivery was $3.3 \mathrm{pmol} / \mathrm{L}$ (IQR: 2.1, 5.2) and $\mathrm{wPTH}$ concentration at delivery was $2.8 \mathrm{pmol} / \mathrm{L}$ (IQR: 1.8, 4.3). In the absence of vitamin D supplementation (i.e. in the placebo group), maternal PTH concentrations significantly increased from enrollment to delivery (Supplementary Fig. 2). Baseline and delivery PTH concentrations among women in the placebo group with enrollment $25(\mathrm{OH}) \mathrm{D}$ concentrations greater than $30 \mathrm{nmol} / \mathrm{L}$ were lower than in women with 25(OH)D concentrations below $30 \mathrm{nmol} / \mathrm{L}$

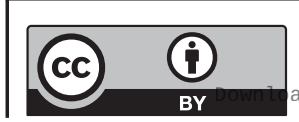

This work is licensed under a Creative Commons Attribution 4.0 International License. 
Table 1 Maternal and infant demographic and clinical characteristics, stratified by baseline (17-24 weeks gestation) maternal iPTH concentrations among mother-infant pairs in a pregnancy cohort in Bangladesh. ${ }^{a}$

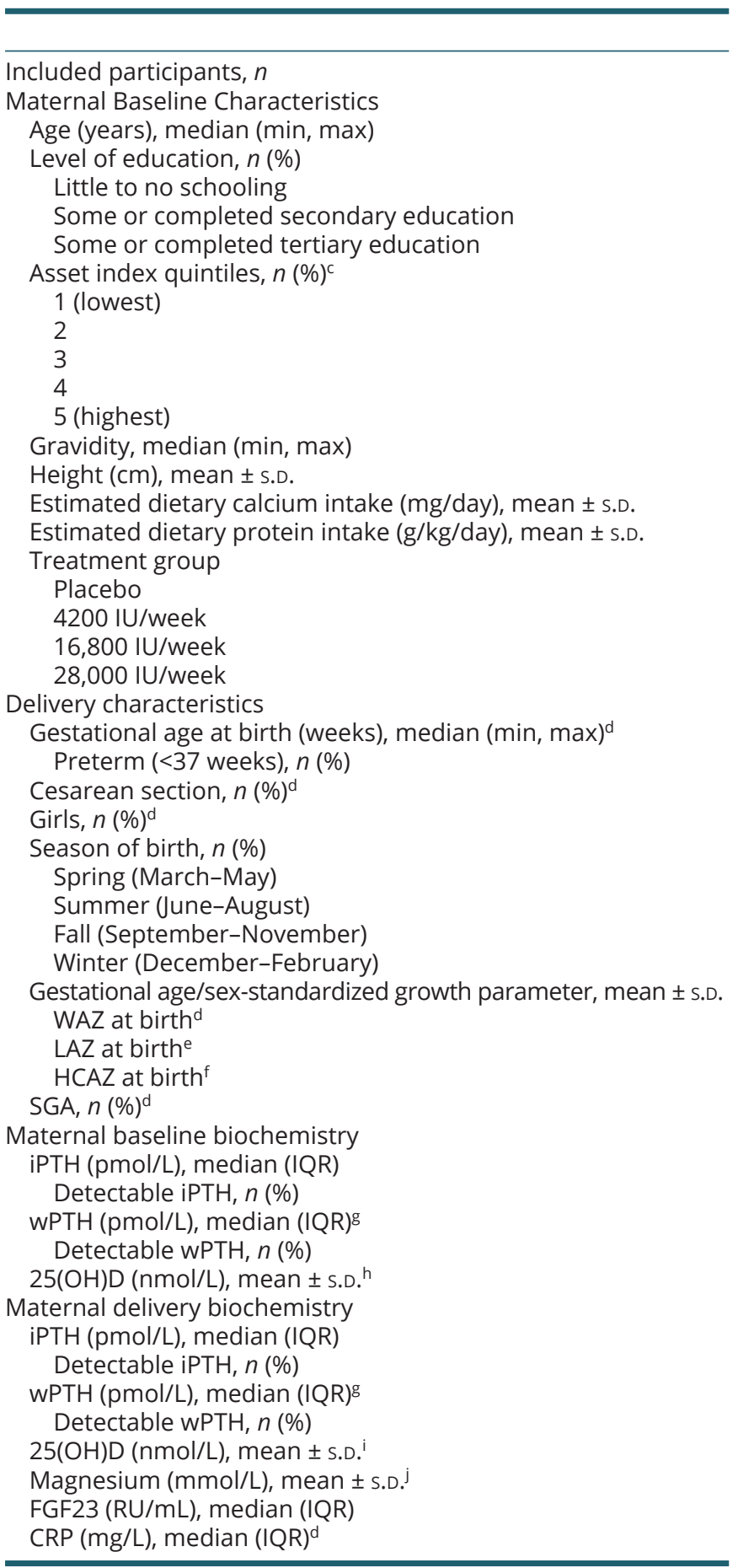

Baseline iPTH $<5.81 \mathrm{pmol} / \mathrm{L}$

426

426

$23(18,38)$

154 (36)

$222(52)$

50 (12)

85 (20)

81 (19)

77 (18)

97 (23)

85 (20)

$2(1,7)$

$151.0 \pm 5.5$

$983.5 \pm 279.2$

$0.8 \pm 0.4$

105 (25)

77 (18)

91 (21)

153 (36)

$$
\begin{gathered}
39.2(33,43) \\
30(7.0) \\
257(60) \\
214(50) \\
70(16) \\
108(25) \\
137(32) \\
111(26) \\
-1.18 \pm 0.85 \\
-0.90 \pm 0.99 \\
-0.61 \pm 0.95 \\
199(47)
\end{gathered}
$$

$3.2(2.4-4.3)$

394 (92)

$2.8(2.1-3.9)$

344 (87)

$28.9 \pm 14.4$

$3.0(1.9-4.5)$

$346(81)$

2.5 (1.7-3.7)

$309(78)$

$85.1 \pm 40.8$

$0.8 \pm 0.1$

$116.4(74.3-201.1)$

$8.3(4.0-18.8)$
Baseline iPTH $\geq 5.81 \mathrm{pmol} / \mathrm{L}$

110

$23(18,38)$

0.94

0.79

38 (35)

61 (55)

11 (10)

$23(21)$

$22(20)$

$23(21)$

$17(15)$

25 (23)

$2(1,9)$

$150.7 \pm 5.5$

$989.2 \pm 245.0$

$0.9 \pm 0.3$

37 (34)

$18(16)$

$18(16)$

37 (34)

0.56

0.75

0.60

0.85

0.26

0.26

$39.1(35,42)$

$3(2.7)$

$73(66)$

$50(45)$

0.09

0.25

0.37

0.29

14 (13)

21 (19)

43 (39)

32 (29)

$-1.15 \pm 0.85$

0.70

$-0.88 \pm 1.02$

$-0.60 \pm 0.98$

0.88

48 (44)

0.97

0.54

$7.3(6.6-9.7)$

$<0.001$

$110(100)$

$5.8(4.2-7.7)$

90 (96)

$22.4 \pm 13.2$

$<0.001$

$<0.001$

$4.9(3.0-7.8)$

$104(95)$

$4.3(2.6-6.5)$

88 (94)

$76.6 \pm 42.4$

$0.8 \pm 0.2$

$124.7(85.0-225.2)$

$11.2(4.0-22.7)$
$<0.001$

$<0.001$

0.07

0.84

0.21

0.14

aBaseline iPTH was split at the 80th percentile of the distribution (5.81 pmol/L). Baseline PTH data was not available for 1 woman in the study (randomized to $4200 \mathrm{IU} /$ week treatment group). ${ }^{\mathrm{b}} \mathrm{P}$-values presented are from Chi-square or Fischer Exact Tests for categorical variables and from ANOVA or Kruskal-Wallis tests for continuous variables. ${ }^{c} n=425$ among women with baseline iPTH $<5.81 \mathrm{pmol} / \mathrm{L} .{ }^{\mathrm{d}} n=424$ among women with baseline $\mathrm{iPTH}<5.81 \mathrm{pmol} / \mathrm{L}$. ${ }^{\mathrm{e}} n=421$ among women with baseline $\mathrm{iPTH}<5.81 \mathrm{pmol} / \mathrm{L}$ and $n=108$ among women with baseline iPTH $\geq 5.81 \mathrm{pmol} / \mathrm{L}$. ${ }^{\mathrm{f}} n=424$ among women with baseline $\mathrm{iPTH}<5.81 \mathrm{pmol} / \mathrm{L}$ and $n=109$ among women with baseline $\mathrm{PTTH} \geq 5.81 \mathrm{pmol} / \mathrm{L}$. $\mathrm{g}_{n}=397$ among women with baseline $\mathrm{iPTH}<5.81 \mathrm{pmol} / \mathrm{L}$ and $n=94$ among women with baseline $\mathrm{iPTH} \geq 5.81 \mathrm{pmol} / \mathrm{L}$. ${ }^{\mathrm{h}} n=423$ among women with baseline iPTH $<5.81 \mathrm{pmol} / \mathrm{L}$. ${ }^{i} n=400$ among women with baseline $\mathrm{iPTH}<5.81 \mathrm{pmol} / \mathrm{L}$ and $n=96$ among women with baseline $\mathrm{iPTH} \geq 5.81 \mathrm{pmol} / \mathrm{L}$. $\mathrm{j} n=398$ among women with baseline iPTH $<5.81 \mathrm{pmol} / \mathrm{L}$ and $n=96$ among women with baseline $\mathrm{iPTH} \geq 5.81 \mathrm{pmol} / \mathrm{L}$.

https://ec.bioscientifica.com

https://doi.org/10.1530/EC-21-0056 (c) 2021 The authors Published by Bioscientifica Ltd

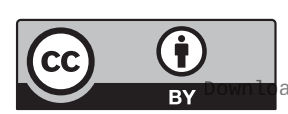

This work is licensed under a Creative Commons Attribution 4.0 International License. 
(Supplementary Table 3). Women with baseline calcium intake above the 50th percentile tended to have lower PTH concentrations at baseline but higher concentrations at delivery compared to women with baseline calcium intake below the 50th percentile (Supplementary Table 3).

\section{Association of maternal PTH and birth size}

iPTH at delivery was significantly positively associated with LAZ, WAZ, and HCAZ in unadjusted linear regression models, but all estimates were attenuated and nonsignificant in multivariable linear regression models (Table 2 and Supplementary Tables 4, 5, 6, 7, 8). In unadjusted and multivariable models, wPTH at delivery was positively associated with WAZ and was associated with a lower risk of being born SGA (Table 2).

There was no significant association between iPTH and birth size in any sensitivity or subgroup analyses (data not shown). Excluding infants who were measured using the Harpenden length board where LAZ was the outcome did not change inferences.

wPTH was not associated with LAZ, WAZ and HCAZ in sensitivity and subgroup analyses, although effect estimates were all positive. Similarly, there were no associations between wPTH and SGA in multivariable subgroup analyses restricted to women randomized to the placebo group, mother-infant pairs with detectable wPTH, boys, and girls. There was, however, a positive association between wPTH and SGA in models adjusting for $25(\mathrm{OH}) \mathrm{D}$ in place of vitamin $\mathrm{D}$ treatment group; in models restricted to term born infants only; and in models restricted to infants with anthropometry collected within $24 \mathrm{~h}$ of birth (data not shown).

Among covariates included in multivariable models, maternal protein intake was negatively associated with birth LAZ, WAZ, and HCAZ, whereas FGF23 concentrations showed positive associations with LAZ, WAZ, HCAZ, and RKL (Supplementary Tables 4, 5, 6, 7 and 8). Among mother-infant pairs randomized to the placebo group, maternal baseline PTH was not associated with newborn size (Supplementary Table 9).

\section{Association of nutritional and endocrine factors with PTH concentrations}

We used linear regression analyses to assess the association between hypothesized nutritional and endocrine factors and maternal PTH concentrations at delivery. Vitamin D supplementation suppressed iPTH and $\mathrm{wPTH}$ concentrations at delivery in a dose-dependent manner (Fig. 1 and Supplementary Tables 10, 11). Similarly, we observed significant negative associations between delivery 25(OH)D and delivery PTH. Serum magnesium and plasma FGF23 were positively associated with iPTH and $\mathrm{wPTH}$ in unadjusted models. In multivariable models, delivery FGF23 remained significantly associated with delivery iPTH and wPTH; however, magnesium only remained associated with wPTH. The association

Table 2 Differences in birth size parameters for a 90\% increase in maternal delivery intact PTH (iPTH) or 73\% increase in maternal whole PTH (WPTH) concentrations among mother-infant pairs from a birth cohort in Dhaka, Bangladesh.

\begin{tabular}{|c|c|c|c|c|c|c|c|c|}
\hline & \multicolumn{4}{|c|}{ Unadjusted models } & \multicolumn{4}{|c|}{ Multivariable model $^{a}$} \\
\hline & $n$ & Difference in size/RR ${ }^{b}$ & $95 \% \mathrm{Cl}$ & $P^{c}$ & $n$ & Difference in size/RR & $95 \% \mathrm{Cl}$ & $P^{c}$ \\
\hline \multicolumn{9}{|l|}{ iPTH } \\
\hline LAZ & 530 & 0.091 & $0.020,0.161$ & 0.012 & 487 & 0.064 & $-0.011,0.139$ & 0.09 \\
\hline WAZ & 535 & 0.070 & $0.010,0.129$ & 0.022 & 490 & 0.056 & $-0.007,0.118$ & 0.08 \\
\hline HCAZ & 534 & 0.082 & $0.015,0.149$ & 0.017 & 489 & 0.047 & $-0.027,0.121$ & 0.21 \\
\hline $\mathrm{RKL}$ & 532 & 0.004 & $-0.050,0.058$ & 0.89 & 487 & -0.004 & $-0.062,0.053$ & 0.88 \\
\hline SGA & 535 & 0.92 & $0.85,0.99$ & 0.023 & 490 & 0.94 & $0.87,1.02$ & 0.17 \\
\hline \multicolumn{9}{|l|}{ wPTH } \\
\hline LAZ & 486 & 0.033 & $-0.033,0.099$ & 0.32 & 479 & 0.018 & $-0.048,0.084$ & 0.60 \\
\hline WAZ & 490 & 0.070 & $0.014,0.125$ & 0.014 & 482 & 0.057 & $0.003,0.112$ & 0.040 \\
\hline $\mathrm{HCAZ}$ & 489 & 0.089 & $0.028,0.151$ & 0.004 & 481 & 0.061 & $-0.003,0.125$ & 0.06 \\
\hline $\mathrm{RKL}$ & 487 & -0.014 & $-0.064,0.036$ & 0.59 & 479 & -0.012 & $-0.062,0.038$ & 0.64 \\
\hline SGA & 490 & 0.91 & $0.85,0.97$ & 0.004 & 482 & 0.92 & $0.86,0.99$ & 0.024 \\
\hline
\end{tabular}

aMultivariable linear or Poisson regression models with robust error variance adjusted for: maternal log PTH, maternal magnesium, maternal log FGF23, maternal log CRP, vitamin D supplementation group, relative protein intake, maternal age, maternal height, maternal education, gravidity, gestational age at birth and season of birth. For models where RKL was the outcome, we additionally adjusted for sex. 'Difference in size presented for LAZ, WAZ, HCAZ, and RKL. Relative risk presented for SGA. Effect sizes are for a 90 and $73 \%$ increase in iPTH and wPTH concentrations, respectively, which reflects a large but plausible difference in PTH concentrations corresponding to the observed effect of high dose vitamin D supplementation (28,000 IU/week) on PTH, vs placebo. ${ }^{c} P<0.05$ considered significant.HCAZ, head circumference-for-gestational age z-scores; LAZ, length-for-gestational age z-scores; RKL, rump-toknee length; SGA, small-for-gestational age; WAZ, weight-for-gestational age z-scores.

https://ec.bioscientifica.com https://doi.org/10.1530/EC-21-0056 (c) 2021 The authors Published by Bioscientifica Ltd

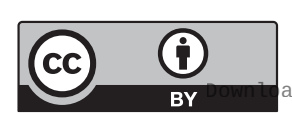

This work is licensed under a Creative Commons Attribution 4.0 International License. ded from Bioscientifica.com at $04 / 26 / 202307: 15: 27 \mathrm{AM}$ 
Regulator of iPTH

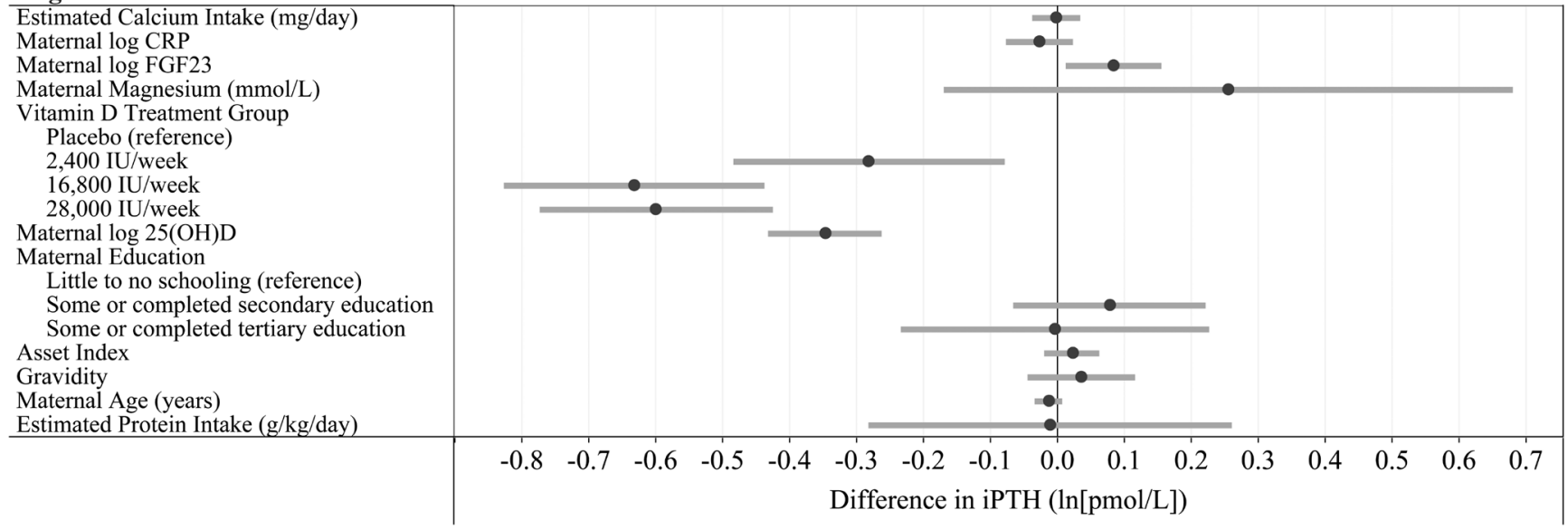

\section{Figure 1}

Multivariable linear regression analysis of the association of maternal calcium intake, protein intake, delivery magnesium concentrations, delivery fibroblast-like growth factor 23 (FGF23), delivery C-reactive protein (CRP), delivery 25-hydroxyvitamin D (25(OH)D) and prenatal vitamin D

supplementation with maternal delivery log intact PTH (iPTH) concentrations. The multivariable model adjusted for each of the regulators as well as baseline protein intake, maternal education, asset index, gravidity, and maternal age at enrollment. Effect estimates represent changes in log iPTH for: a $100 \mathrm{mg} /$ day increase in calcium intake; a unit increase in log CRP, FGF23 and 25(OH)D; and a $1 \mathrm{mmol} / \mathrm{L}$ increase in magnesium. Black dots represent the regression coefficient from multivariable linear regression models, gray bars represent the $95 \% \mathrm{Cls}$ of the regression coefficient. The estimate for maternal $\log 25(\mathrm{OH}) \mathrm{D}$ was estimated in a separate model, replacing vitamin $\mathrm{D}$ treatment group.

between magnesium and iPTH was primarily attenuated by inclusion of vitamin D supplementation in the model. Daily calcium intake and CRP concentrations were not found to be associated with delivery PTH.

\section{Direct and indirect associations of PTH and its regulators with newborn size using path analysis}

The final path models demonstrated very good model fit (iPTH model: RMSEA < 0.001, TLI=1.035; wPTH model: RMSEA $<0.001$, TLI $=1.028$ ). Similar to linear regression models, vitamin D supplementation suppressed PTH at delivery in a dose-dependent manner; the lowest dose at which maximal suppression was achieved was the 16,800 IU/week group, with no additional suppression of PTH in the 28,000 IU/week group (Supplementary Tables 12 and 13). There was a significant negative direct and total effect of delivery $25(\mathrm{OH}) \mathrm{D}$ on PTH concentrations. The direct effect of vitamin D supplementation was not significant; however, the indirect effect of vitamin D supplementation was statistically significant, indicating the effect of prenatal vitamin D supplementation on delivery PTH was substantially mediated by delivery 25(OH)D (Fig. 2 and Supplementary Table 12). The indirect effect of vitamin D supplementation on iPTH in the 16,800 IU/week group and $28,000 \mathrm{IU} /$ week group (compared to placebo) accounted for $65 \%$, and $74 \%$ of the total effect, respectively.

Maternal delivery FGF23 was significantly associated with delivery iPTH and wPTH concentrations.
Magnesium had a positive direct effect on wPTH. The highest dose of vitamin D supplementation suppressed delivery magnesium compared to placebo, with no significant effect at intermediate doses, although effect estimates indicated a dose-dependent response (Fig. 2).

iPTH at delivery was positively associated with LAZ at birth (direct and total effects) (Fig. 2 and Supplementary Table 12). WPTH at delivery was positively associated with birth WAZ (Supplementary Table 13). Magnesium concentrations were negatively associated with LAZ and delivery FGF23 was positively associated with LAZ, WAZ, and HCAZ (Fig. 2 and Supplementary Table 12). The indirect effect of FGF23, mediated by iPTH, accounted for only $4.2,3.9$, and $3.8 \%$ of the total effect of FGF23 on LAZ, WAZ, and HCAZ, respectively.

Analyses assessing whether supplementary vitamin $\mathrm{D}$ or tertiles of usual dietary calcium intake modified the iPTH-LAZ association revealed no vitamin D-iPTH or calcium-iPTH interactions relevant to the association of iPTH and infant length (Supplementary Fig. 3). Similarly, there was no vitamin D-wPTH or calcium-wPTH interactions relevant to the association of $\mathrm{WPTH}$ and infant weight (Supplementary Fig. 4).

\section{Discussion}

In a Bangladeshi cohort with a high prevalence of SGA, low dietary calcium intake, and high prevalence of 


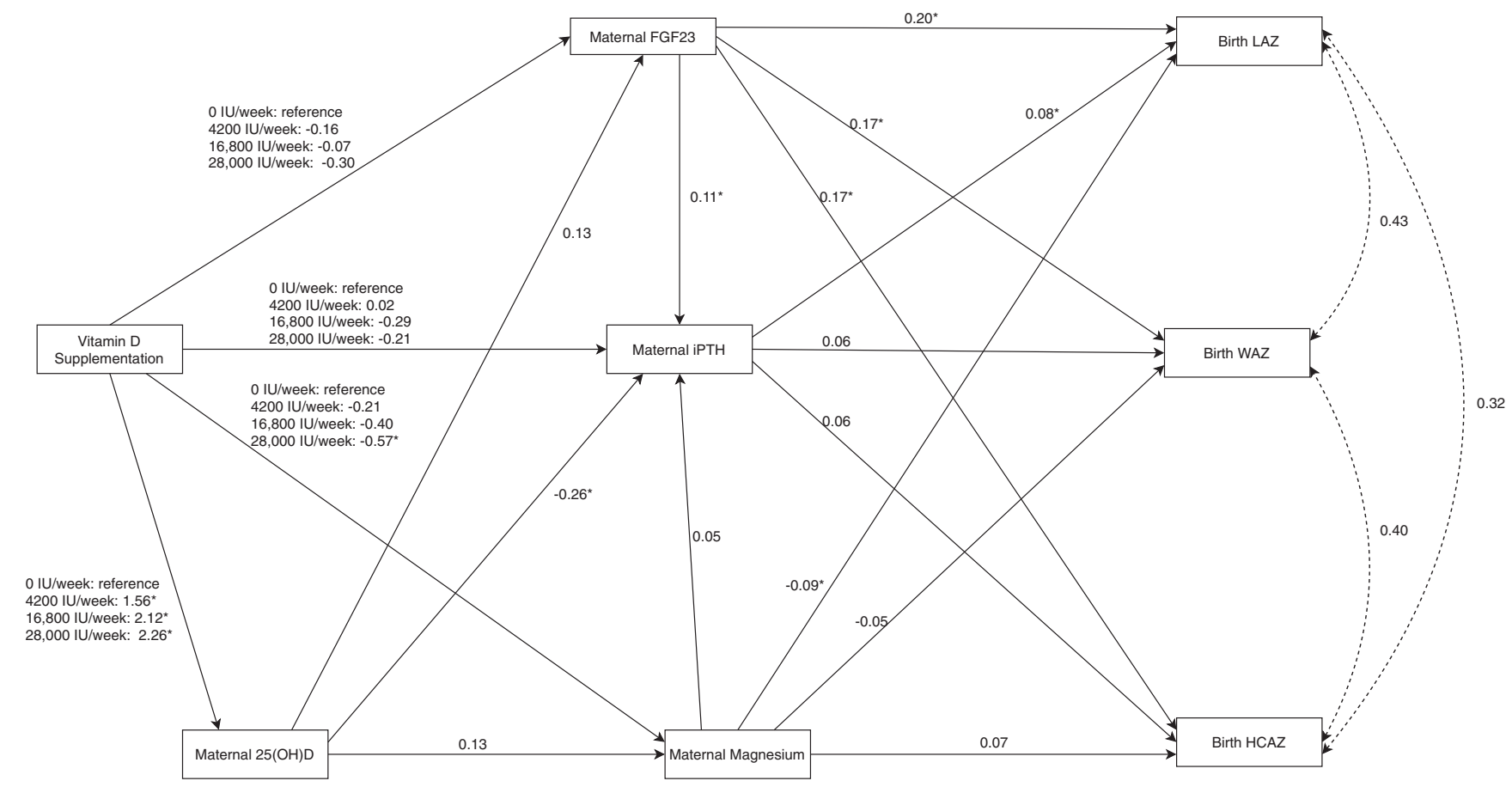

Figure 2

Path diagram showing the direct and indirect pathways by which maternal delivery intact parathyroid hormone (iPTH) and its associated nutritional and endocrine factors are associated with newborn size at birth. Each of the arrows denote tested paths and are labeled with the standardized path coefficients, which represent the direct effect of the explanatory variable on the dependent variable. Double headed arrows represent covariances between variables. Asterisks denote statistically significant path coefficients $(P<0.05)$. Confounders included in the path analysis model are not shown in this figure.

vitamin D deficiency, we did not find strong evidence to support an important role for PTH in the regulation of fetal growth. Although there was a positive association between maternal delivery iPTH concentrations and birth length in a path analysis model, the effect sizes were small, and inferences were not supported by models adjusted for confounders. Similarly, while wPTH was positively associated with birthweight in path analysis and multivariable linear regression models, overall effect sizes were small. Effect estimates across all models assessing the association of iPTH and wPTH with birth anthropometry were positive, which was contrary to our hypothesized negative effect of maternal PTH on fetal growth. These results are generally consistent with the previously reported null effect of vitamin D supplementation on birth size in the main trial report (34).

Morley and colleagues previously reported a positive association between late-pregnancy iPTH and birthweight in an Australian cohort (22). Although our estimates for the association of iPTH and wPTH with birthweight were similar, the effect size for the wPTH-birthweight association was more precise (i.e. the standard errors of the estimates were smaller). In contrast, in a study conducted in a cohort of Pakistani women living in Oslo, delivery iPTH was negatively associated with birth length; however, this study was relatively small $(\mathrm{N}=30)$ and did not account for confounders (37). In a US pregnancy cohort, there were negative associations of early gestational iPTH $(13.8 \pm 5.6$ weeks of gestation) with birth length and head circumference, and women who experienced 'calcium metabolic stress' (defined as insufficient calcium and/or vitamin D intake accompanied by elevated PTH) had a relatively increased risk of SGA birth, lower birth length, and lower head circumference (20). However, these findings contrast observations from a cohort of Irish pregnant women in whom PTH in early pregnancy and calcium metabolic stress at $<17$ weeks were not associated with SGA, after adjustment for confounders (21).

The timing of PTH measurement during pregnancy may partly explain inconsistent findings across these studies. We and others have observed an increase in PTH concentrations particularly in the third trimester of pregnancy $(15,17,18,19,40)$. As transplacental calcium transfer occurs to a large extent during the third trimester (16), the increase in PTH may reflect an appropriate physiological response to the demands of fetal skeletal growth. We speculate that higher PTH concentrations early in pregnancy, especially in the context of vitamin D

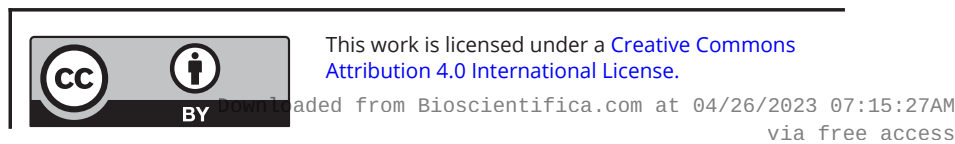


deficiency, is a marker of a suboptimal environment for fetal growth, whereas an elevation in PTH later in pregnancy indicates an appropriate homeostatic response aimed at mobilizing maternal calcium stores to support fetal skeletal growth. We could not corroborate this hypothesis in the present cohort, as there was no association of baseline PTH (17-24 weeks' gestation) with birth size in sensitivity analyses; this may in part be because baseline PTH in our cohort was mid-gestational, and therefore considerably later in pregnancy than in the study by Scholl and colleagues (20). In addition, due to relatively small sample sizes, we were not able to assess the association of birth size with calcium metabolic stress at delivery as defined by Scholl et al. (20). However, we did assess whether vitamin D treatment group or calcium intake (defined as tertiles of intake) modified the iPTHbirth length and wPTH-birthweight associations, and did not find any significant interactions. Therefore, at delivery, the lack of strong association between PTH and infant length and birthweight was similar across varying levels of vitamin D and calcium intake.

We found that the suppressive effect of prenatal vitamin D supplementation on PTH was largely mediated by $25(\mathrm{OH}) \mathrm{D}$. If the observed positive association between iPTH and infant length, and between wPTH and infant weight in our path analysis models are true effects, then we would expect a negative effect of vitamin D supplementation on birth size. This is because the PTH-mediated effect of vitamin D supplementation on birth size is by definition the mathematical product of the direct effects of vitamin D on PTH and of PTH on birth size. Consistent with this notion, the observed indirect effect of vitamin D on birth size was negative, although effect estimates were small and not significant. In the MDIG trial, prenatal vitamin D supplementation indicated very small non-significant total negative effects on birth LAZ, WAZ, and HCAZ, compared to placebo (34). This may suggest that vitamin D is detrimental to fetal growth; however, contrary to this finding, a recent umbrella review of systematic reviews of prenatal vitamin D supplementation found no evidence for an effect of vitamin $\mathrm{D}$ on low birthweight and a protective effect on SGA, although quality of evidence was low (41).

Vitamin D also suppressed magnesium concentrations at the highest dose, with an apparent dose-dependent effect. Few studies have reported on the causal effect of vitamin D supplementation on magnesium concentrations. One study conducted in Iran found no effect of vitamin D supplementation (single 50,000 IU bolus dose over 8 weeks) vs placebo on magnesium concentrations among hypertensive patients with vitamin D deficiency (42). Similar null effects of vitamin D supplementation $(80 \mu \mathrm{g} /$ day) on magnesium were noted among obese patients after surgery (43). These studies assessed doses lower than the highest dose group in the MDIG trial, which was the only group in which we observed a significant effect of vitamin D. Magnesium was positively associated with wPTH in multivariable models and was also negatively associated with birth length. The negative association between magnesium and birth length did not appear to be mediated by PTH. Furthermore, the magnesium-mediated indirect effect of vitamin D on birth length was small, but positive (i.e. opposite the negative indirect effect of vitamin $\mathrm{D}$ on birth size mediated by PTH). It is unclear why we observed a negative association between maternal magnesium and birth length. One clinical observational study in Ireland reported a positive association between third trimester magnesium intake and birth length, while another study in Poland found no association between placental magnesium and birth size $(44,45)$. Importantly, our observed effect size of the magnesium-birth length relationship was relatively small and we speculate that there may be other unmeasured pathways that confounded the magnesium-birth length association.

Confirming previous in vivo and clinical studies of patients with renal insufficiency $(27,28,46)$, we observed a positive association between FGF23 and PTH. Due to the cross-sectional nature of this analysis, we cannot conclude whether FGF23 was a regulator of PTH or vice versa; however, if PTH was a regulator of FGF23, we would have expected a total effect of vitamin D supplementation on FGF23, which was not observed. This null effect is consistent with findings of post-hoc analyses from another randomized controlled trial of Austrian hypertensive patients, in whom vitamin D3 supplementation had no effect on FGF23 after adjusting for baseline FGF23 (47). Therefore, although the estimated association between FGF23 and PTH was based on cross-sectional data, the observed null effect of vitamin D on FGF23 suggest that FGF23 is a regulator of PTH.

We observed a robust positive association between FGF23 and birth length, weight, and head circumference as well as an association of higher FGF23 with lower risk of being born SGA. These associations were independent of PTH, and the effect sizes were important. For example, the magnitude of the association for a 1 SD increase in $\log$ FGF23 with birth length was almost three-quarters the magnitude of association for a 1 SD increase in maternal height, which is known to correlate strongly

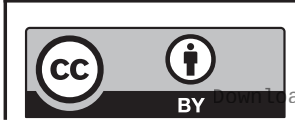

This work is licensed under a Creative Commons Attribution 4.0 International License. ded from Bioscientifica.com at 04/26/2023 07:15:27AM 
with birth length. To our knowledge, no study has directly reported on the association of maternal FGF23 with birth anthropometry. FGF23 may be implicated in fetal long bone growth by promoting hypertrophy and mineralization of chondrocytes $(48,49,50)$. However, maternal FGF23 likely does not cross the placenta (51), so any effects it may have on the growing fetus would be through mediated pathways, possibly through its regulatory effects on phosphorous (52).

We did not find strong evidence to support roles for habitual calcium or protein intakes in the regulation of PTH activity in late pregnancy. The lack of apparent effect of calcium intake on maternal PTH concentrations was in line with findings from a cohort of pregnant women in Ireland (53). Although we did not expect protein intake to be a major determinant of PTH, the negative association between estimated protein intake and birth size was consistent with evidence from previous observational studies and trials $(54,55,56,57,58,59)$. The association between maternal protein intake and birth size may be U-shaped such that protein intake that is too high or too low could be detrimental to the growing fetus (55), but we did not observe such a U-shaped association of protein intake with birth size.

A strength of the study was the measurement of wPTH in addition to the conventional analyte, iPTH; all previously published observational studies assessing PTH and birth size used iPTH assays $(20,21,22,37)$. Because iPTH assays measure the whole PTH peptide as well as fragments that are missing the active n-terminus and thus unable to bind the PTH1R, we had expected associations to be stronger with wPTH given that it is a more specific measure of the bioactive PTH peptide (60). Effect estimates for wPTH and birth length were smaller than the corresponding estimate for iPTH, although associations with WAZ were slightly stronger for wPTH. Associations of PTH with hypothesized regulators were also not consistently more evident using wPTH, with the exception of its association with serum magnesium. The iPTH and wPTH assays were from the same manufacturer and had comparable inter- and intra-assay CVs, so the similar findings do not seem attributable to wPTH assay performance. Despite our expectations, measuring wPTH did not appear to contribute additional insights beyond what was observed from measuring iPTH.

Our study had limitations that are important to acknowledge. The FFQ utilized in this study was nonquantitative and not previously validated, which may have reduced the accuracy of estimated total dietary calcium and protein intake. Women in the MDIG trial were co-supplemented with calcium which may have mitigated any association of calcium intake with PTH concentrations. Although many of the analyses were based on a cross-sectional observational design (e.g. variables simultaneously measured at birth), we leveraged the randomized placebo-controlled trial design of the MDIG trial to estimate causal effects of vitamin D supplementation on PTH, magnesium, and FGF23. The mediation analyses were grounded in the literature and specific a priori hypotheses; therefore, while we are unable to make causal inferences, this study provides important insights into potential mechanisms that influence fetal growth and novel candidate biomarkers that should be further explored (e.g. FGF23). We were also unable to assess associations of venous cord PTH in this study, owing to large proportions of undetectable concentrations (>90\%), which would have allowed us to measure the direct association of PTH in the fetal circulation with fetal growth. Lastly, we recognize the potential for selection bias in our analysis, since this study sample was chosen from an already selected group of participants in a randomized controlled trial.

In conclusion, maternal delivery PTH is not a biomarker of IUGR, and elevated maternal PTH at delivery does not appear to impair fetal skeletal growth in a population with a high prevalence of maternal undernutrition and IUGR. Future studies should aim to further examine the potential role of maternal FGF23, magnesium and protein intake in pregnancy on fetal growth.

\section{Supplementary materials}

This is linked to the online version of the paper at https://doi.org/10.1530/ EC-21-0056.

\section{Declaration of interest}

The authors declare that there is no conflict of interest that could be perceived as prejudicing the impartiality of the research reported.

\section{Funding}

The MDIG trial was funded by the Bill and Melinda Gates Foundation (OPP1066764).

\section{Author contribution statement}

$H$ Q, D E R, A D G, and N P designed research; H Q, D E R, E P, and A A M conducted research; $H Q$ analyzed data; and $H Q$, and $D E R$ wrote the paper. $H$ Q and D E R had primary responsibility for final content. All authors read and approved the final manuscript.

\section{Acknowledgements}

The authors wish to thank all MDIG trial participants, personnel and co-investigators; Dr Robert Bandsma at the Centre for Global Child 
Health (CGCH), The Hospital for Sick Children (Toronto, Canada) for sharing laboratory resources for this project; Akpevwe Onoyovwi at the $\mathrm{CGCH}$, The Hospital for Sick Children (Toronto, Canada) for assistance with magnesium measurements; and Hayley Craig-Barnes and Ashley St. Pierre of the Analytical Facility for Bioactive Molecules (AFBM), The Hospital for Sick Children (Toronto, Canada) for assistance with 25-hydroxyvitamin D, CRP, and FGF23 measurements. The MDIG trial was funded by the Bill and Melinda Gates foundation.

\section{References}

1 Victora CG, Adair L, Fall C, Hallal PC, Martorell R, Richter L, Sachdev HS \& Maternal and Child Undernutrition Study Group. Maternal and child undernutrition: consequences for adult health and human capital. Lancet 2008371 340-357. (https://doi. org/10.1016/S0140-6736(07)61692-4)

2 Kozuki N, Katz J, LeClerq SC, Khatry SK, West KP \& Christian P. Risk factors and neonatal/infant mortality risk of small-for-gestationalage and preterm birth in rural Nepal. Journal of Maternal-Fetal and Neonatal Medicine 201528 1019-1025. (https://doi.org/10.3109/1476 7058.2014.941799)

3 Risnes KR, Vatten LJ, Baker JL, Jameson K, Sovio U, Kajantie E, Osler M, Morley R, Jokela M, Painter RC, et al. Birthweight and mortality in adulthood: a systematic review and meta-analysis. International Journal of Epidemiology 201140 647-661. (https://doi. org/10.1093/ije/dyq267)

4 Larroque B, Bertrais S, Czernichow P \& Léger J. School difficulties in 20-year-olds who were born small for gestational age at term in a regional cohort study. Pediatrics 2001108 111-115. (https://doi. org/10.1542/peds.108.1.111)

5 Wennerström EC, Simonsen J \& Melbye M. Long-term survival of individuals born small and large for gestational age. PLOS ONE 2015 10 e0138594. (https://doi.org/10.1371/journal.pone.0138594)

6 Morris SS, Victora CG, Barros FC, Halpern R, Menezes AM, César JA, Horta BL \& Tomasi E. Length and ponderal index at birth: associations with mortality, hospitalizations, development and postnatal growth in Brazilian infants. International Journal of Epidemiology 199827 242-247. (https://doi.org/10.1093/ije/27.2.242)

7 Victora CG, Villar J, Barros FC, Ismail LC, Chumlea C, Papageorghiou AT, Bertino E, Ohuma EO, Lambert A, Carvalho M, et al. Anthropometric characterization of impaired fetal growth: risk factors for and prognosis of newborns with stunting or wasting. JAMA Pediatrics 2015169 e151431. (https://doi.org/10.1001/jamapediatrics.2015.1431)

8 Ott WJ. Fetal femur length, neonatal crown-heel length, and screening for intrauterine growth retardation. Obstetrics and Gynecology 198565 460-464.

9 Lee AC, Kozuki N, Cousens S, Stevens GA, Blencowe H, Silveira MF, Sania A, Rosen HE, Schmiegelow C, Adair LS, et al. Estimates of burden and consequences of infants born small for gestational age in low and middle income countries with INTERGROWTH-21(st) standard: analysis of CHERG datasets. BMJ 2017358 j3677. (https:// doi.org/10.1136/bmj.j3677)

10 Svefors P, Sysoev O, Ekstrom EC, Persson LA, Arifeen SE, Naved RT, Rahman A, Khan AI \& Selling K. Relative importance of prenatal and postnatal determinants of stunting: data mining approaches to the MINIMat cohort, Bangladesh. BMJ Open 20199 e025154. (https:// doi.org/10.1136/bmjopen-2018-025154)

11 Arifeen SE, Black RE, Caulfield LE, Antelman G, Baqui AH, Nahar Q, Alamgir S \& Mahmud H. Infant growth patterns in the slums of Dhaka in relation to birth weight, intrauterine growth retardation, and prematurity. American Journal of Clinical Nutrition $2000 \mathbf{7 2}$ 1010-1017. (https://doi.org/10.1093/ajcn/72.4.1010)

12 Silva BC \& Bilezikian JP. Parathyroid hormone: anabolic and catabolic actions on the skeleton. Current Opinion in Pharmacology 201522 41-50. (https://doi.org/10.1016/j.coph.2015.03.005)
13 Habener JF, Rosenblatt M \& Potts JT. Parathyroid hormone: biochemical aspects of biosynthesis, secretion, action, and metabolism. Physiological Reviews 198464 985-1053. (https://doi. org/10.1152/physrev.1984.64.3.985)

14 Northrop G, Misenhimer HR \& Becker FO. Failure of parathyroid hormone to cross the nonhuman primate placenta. American Journal of Obstetrics and Gynecology 1977129 449-453. (https://doi. org/10.1016/0002-9378(77)90593-2)

15 Young BE, McNanley TJ, Cooper EM, McIntyre AW, Witter F, Harris ZL \& O'Brien KO. Vitamin D insufficiency is prevalent and vitamin $\mathrm{D}$ is inversely associated with parathyroid hormone and calcitriol in pregnant adolescents. Journal of Bone and Mineral Research 201227 177-186. (https://doi.org/10.1002/jbmr.526)

16 Specker B. Vitamin D requirements during pregnancy. American Journal of Clinical Nutrition 200480 (Supplement) 1740S-1747S. (https://doi.org/10.1093/ajcn/80.6.1740S)

17 Singh HJ, Mohammad NH \& Nila A. Serum calcium and parathormone during normal pregnancy in Malay women. Journal of Maternal-Fetal Medicine 19998 95-100. (https://doi.org/10.1002/ (SICI)1520-6661(199905/06)8:3<95::AID-MFM5>3.0.CO;2-4)

18 Seely EW, Brown EM, DeMaggio DM, Weldon DK \& Graves SW. A prospective study of calciotropic hormones in pregnancy and post partum: reciprocal changes in serum intact parathyroid hormone and 1,25-dihydroxyvitamin D. American Journal of Obstetrics and Gynecology 1997176 214-217. (https://doi.org/10.1016/s00029378(97)80039-7)

19 Roth DE, Al Mahmud A, Raqib R, Akhtar E, Perumal N, Pezzack B $\&$ Baqui AH. Randomized placebo-controlled trial of high-dose prenatal third-trimester vitamin D3 supplementation in Bangladesh: the AViDD trial. Nutrition Journal 201312 47. (https://doi. org/10.1186/1475-2891-12-47)

20 Scholl TO, Chen X \& Stein TP. Maternal calcium metabolic stress and fetal growth. American Journal of Clinical Nutrition 201499 918-925. (https://doi.org/10.3945/ajcn.113.076034)

21 Hemmingway A, Kenny LC, Malvisi L \& Kiely ME. Exploring the concept of functional vitamin D deficiency in pregnancy: impact of the interaction between 25-hydroxyvitamin D and parathyroid hormone on perinatal outcomes. American Journal of Clinical Nutrition 2018108 821-829. (https://doi.org/10.1093/ajcn/nqy150)

22 Morley R, Carlin JB, Pasco JA \& Wark JD. Maternal 25-hydroxyvitamin D and parathyroid hormone concentrations and offspring birth size. Journal of Clinical Endocrinology and Metabolism 200691 906-912. (https://doi.org/10.1210/jc.2005-1479)

23 Stumpf WE, Sar M, Reid FA, Tanaka Y \& DeLuca HF. Target cells for 1,25-dihydroxyvitamin D3 in intestinal tract, stomach, kidney, skin, pituitary, and parathyroid. Science 1979206 1188-1190. (https://doi. org/10.1126/science.505004)

24 Silver J, Naveh-Many T, Mayer H, Schmelzer HJ \& Popovtzer MM. Regulation by vitamin D metabolites of parathyroid hormone gene transcription in vivo in the rat. Journal of Clinical Investigation 1986 78 1296-1301. (https://doi.org/10.1172/JCI112714)

25 Riccardi D \& Valenti G. Localization and function of the renal calcium-sensing receptor. Nature Reviews: Nephrology 201612 414-425. (https://doi.org/10.1038/nrneph.2016.59)

26 Krajisnik T, Björklund P, Marsell R, Ljunggren O, Akerström G, Jonsson KB, Westin G \& Larsson TE. Fibroblast growth factor-23 regulates parathyroid hormone and 1alpha-hydroxylase expression in cultured bovine parathyroid cells. Journal of Endocrinology 2007 195 125-131. (https://doi.org/10.1677/JOE-07-0267)

27 Kawata T, Imanishi Y, Kobayashi K, Miki T, Arnold A, Inaba M \& Nishizawa Y. Parathyroid hormone regulates fibroblast growth factor-23 in a mouse model of primary hyperparathyroidism. Journal of the American Society of Nephrology 200718 2683-2688. (https://doi. org/10.1681/ASN.2006070783)

28 Westerberg PA, Linde T, Wikström B, Ljunggren O, Stridsberg M \& Larsson TE. Regulation of fibroblast growth factor-23 in chronic

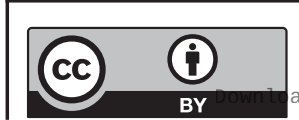

This work is licensed under a Creative Commons Attribution 4.0 International License. ded from Bioscientifica, com at 04/26/2023 07:15:27AM 
kidney disease. Nephrology, Dialysis, Transplantation 200722 3202-3207. (https://doi.org/10.1093/ndt/gfm347)

29 Andrukhova O, Streicher C, Zeitz U \& Erben RG. FGF23 and parathyroid hormone signaling interact in kidney and bone. Molecular and Cellular Endocrinology 2016436 224-239. (https://doi. org/10.1016/j.mce.2016.07.035)

30 Knab VM, Corbin B, Andrukhova O, Hum JM, Ni P, Rabadi S, Maeda A, White KE, Erben RG, Jüppner H, et al. Acute parathyroid hormone injection increases C-terminal but not intact fibroblast growth factor 23 levels. Endocrinology 2017158 1130-1139. (https:// doi.org/10.1210/en.2016-1451)

31 Cheng SP, Liu CL, Liu TP, Hsu YC \& Lee JJ. Association between parathyroid hormone levels and inflammatory markers among US adults. Mediators of Inflammation 20142014 709024. (https://doi. org/10.1155/2014/709024)

32 Reid D, Toole BJ, Knox S, Talwar D, Harten J, O’Reilly DS, Blackwell S, Kinsella J, McMillan DC \& Wallace AM. The relation between acute changes in the systemic inflammatory response and plasma 25-hydroxyvitamin D concentrations after elective knee arthroplasty. American Journal of Clinical Nutrition 201193 1006-1011. (https:// doi.org/10.3945/ajcn.110.008490)

33 Vetter T \& Lohse MJ. Magnesium and the parathyroid. Current Opinion in Nephrology and Hypertension 200211 403-410. (https://doi. org/10.1097/00041552-200207000-00006)

34 Roth DE, Morris SK, Zlotkin S, Gernand AD, Ahmed T, Shanta SS, Papp E, Korsiak J, Shi J, Islam MM, et al. Vitamin D supplementation in pregnancy and lactation and infant growth. New England Journal of Medicine 2018379 1881-1882. (https://doi.org/10.1056/ NEJMc1811310)

35 Roth DE, Gernand AD, Morris SK, Pezzack B, Islam MM, Dimitris MC, Shanta SS, Zlotkin SH, Willan AR, Ahmed T, et al. Maternal vitamin D supplementation during pregnancy and lactation to promote infant growth in Dhaka, Bangladesh (MDIG trial): study protocol for a randomized controlled trial. Trials 201516 300. (https://doi.org/10.1186/s13063-015-0825-8)

36 Villar J, Ismail LC, Victora CG, Ohuma EO, Bertino E, Altman DG, Lambert A, Papageorghiou AT, Carvalho M, Jaffer YA, et al. International standards for newborn weight, length, and head circumference by gestational age and sex: the newborn crosssectional study of the INTERGROWTH-21st project. Lancet 2014384 857-868. (https://doi.org/10.1016/S0140-6736(14)60932-6)

37 Brunvand L, Quigstad E, Urdal P \& Haug E. Vitamin D deficiency and fetal growth. Early Human Development 199645 27-33. (https://doi. org/10.1016/0378-3782(95)01719-4)

38 Schleicher RL, Encisco SE, Chaudhary-Webb M, Paliakov E, McCoy LF \& Pfeiffer CM. Isotope dilution ultra performance liquid chromatography-tandem mass spectrometry method for simultaneous measurement of 25-hydroxyvitamin D2, 25-hydroxyvitamin D3 and 3-epi-25-hydroxyvitamin D3 in human serum. Clinica Chimica Acta: International Journal of Clinical Chemistry 2011412 1594-1599. (https://doi.org/10.1016/j.cca.2011.05.010)

39 Zou G. A modified Poisson regression approach to prospective studies with binary data. American Journal of Epidemiology 2004159 702-706. (https://doi.org/10.1093/aje/kwh090)

40 Gustafsson MK, Romundstad PR, Stafne SN, Helvik AS, Stunes AK, Mørkved S, Salvesen KÅ, Thorsby PM \& Syversen U. Alterations in the vitamin $\mathrm{D}$ endocrine system during pregnancy: a longitudinal study of 855 healthy Norwegian women. PLOS ONE $2018 \mathbf{1 3}$ e0195041. (https://doi.org/10.1371/journal.pone.0195041)

41 Bialy L, Fenton T, Shulhan-Kilroy J, Johnson DW, McNeil DA \& Hartling L. Vitamin D supplementation to improve pregnancy and perinatal outcomes: an overview of 42 systematic reviews. BMJ Open 202010 e032626. (https://doi.org/10.1136/bmjopen-2019-032626)

42 Al-Daghri NM, Alkharfy KM, Khan N, Alfawaz HA, Al-Ajlan AS, Yakout SM \& Alokail MS. Vitamin D supplementation and serum levels of magnesium and selenium in type 2 diabetes mellitus patients: gender dimorphic changes. International Journal for Vitamin and Nutrition Research 201484 27-34. (https://doi.org/10.1024/03009831/a000190)

43 Wolf E, Utech M, Stehle P, Büsing M, Helfrich HP, Stoffel-Wagner B, Egert S, Alteheld B, Riege R, Knapp A, et al. Oral high-dose vitamin D dissolved in oil raised serum 25-hydroxy-vitamin D to physiological levels in obese patients after sleeve gastrectomy - a double-blind, randomized, and placebo-controlled trial. Obesity Surgery 201626 1821-1829. (https://doi.org/10.1007/s11695-015-2004-0)

44 Horan MK, McGowan CA, Gibney ER, Donnelly JM \& McAuliffe FM. The association between maternal dietary micronutrient intake and neonatal anthropometry - secondary analysis from the ROLO study. Nutrition Journal 201514 105. (https://doi.org/10.1186/s12937-0150095-z)

45 Mazurek D, Łoźna K \& Bronkowska M. The concentration of selected elements in the placenta according to selected sociodemographic factors and their effect on birth mass and birth length of newborns. Journal of Trace Elements in Medicine and Biology 2019126425. (https://doi.org/10.1016/j.jtemb.2019.126425)

46 Shigematsu T, Kazama JJ, Yamashita T, Fukumoto S, Hosoya T, Gejyo F \& Fukagawa M. Possible involvement of circulating fibroblast growth factor 23 in the development of secondary hyperparathyroidism associated with renal insufficiency. American Journal of Kidney Diseases 200444 250-256. (https://doi. org/10.1053/j.ajkd.2004.04.029)

47 Trummer C, Schwetz V, Pandis M, Grübler MR, Verheyen N, Gaksch M, Zittermann A, März W, Aberer F, Steinkellner J, et al. Effects of vitamin D supplementation on FGF23: a randomizedcontrolled trial. European Journal of Nutrition 201958 697-703. (https://doi.org/10.1007/s00394-018-1672-7)

48 Masuyama R, Stockmans I, Torrekens S, Van Looveren R, Maes C, Carmeliet P, Bouillon R \& Carmeliet G. Vitamin D receptor in chondrocytes promotes osteoclastogenesis and regulates FGF23 production in osteoblasts. Journal of Clinical Investigation 2006116 3150-3159. (https://doi.org/10.1172/JCI29463)

49 Guibert M, Gasser A, Kempf H \& Bianchi A. Fibroblast-growth factor 23 promotes terminal differentiation of ATDC5 cells. PLOS ONE 201712 e0174969. (https://doi.org/10.1371/journal. pone.0174969)

50 Raimann A, Ertl DA, Helmreich M, Sagmeister S, Egerbacher M \& Haeusler G. Fibroblast growth factor 23 and klotho are present in the growth plate. Connective Tissue Research 201354 108-117. (https:// doi.org/10.3109/03008207.2012.753879)

51 Ohata Y, Arahori H, Namba N, Kitaoka T, Hirai H, Wada K, Nakayama M, Michigami T, Imura A, Nabeshima Y, et al. Circulating levels of soluble alpha-klotho are markedly elevated in human umbilical cord blood. Journal of Clinical Endocrinology and Metabolism 201196 E943-E947. (https://doi.org/10.1210/jc.2010-2357)

52 Liu S, Tang W, Zhou J, Stubbs JR, Luo Q, Pi M \& Quarles LD. Fibroblast growth factor 23 is a counter-regulatory phosphaturic hormone for vitamin D. Journal of the American Society of Nephrology 200617 1305-1315. (https://doi.org/10.1681/ASN.2005111185)

53 Hemmingway A, O'Callaghan KM, Hennessy Á, Hull GLJ, Cashman KD \& Kiely ME. Interactions between vitamin D status, calcium intake and parathyroid hormone concentrations in healthy white-skinned pregnant women at northern latitude. Nutrients 2018 10 916. (https://doi.org/10.3390/nu10070916)

54 Andreasyan K, Ponsonby AL, Dwyer T, Morley R, Riley M, Dear K $\&$ Cochrane J. Higher maternal dietary protein intake in late pregnancy is associated with a lower infant ponderal index at birth. European Journal of Clinical Nutrition 200761 498-508. (https://doi. org/10.1038/sj.ejcn.1602552)

55 Switkowski KM, Jacques PF, Must A, Kleinman KP, Gillman MW \& Oken E. Maternal protein intake during pregnancy and linear growth https://ec.bioscientifica.com https://doi.org/10.1530/EC-21-0056
(C) 2021 The authors Published by Bioscientifica Ltd

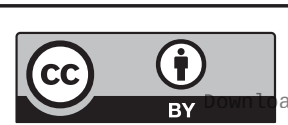

This work is licensed under a Creative Commons Attribution 4.0 International License. ded from Bioscientifica.com at 04/26/2023 07:15:27AM 
in the offspring. American Journal of Clinical Nutrition $2016 \mathbf{1 0 4}$ 1128-1136. (https://doi.org/10.3945/ajcn.115.128421)

56 Sloan NL, Lederman SA, Leighton J, Himes JH \& Rush D. The effect of prenatal dietary protein intake on birth weight. Nutrition Research 200121 129-139. (https://doi.org/10.1016/S02715317(00)00258-X)

57 Ota E, Hori H, Mori R, Tobe-Gai R \& Farrar D. Antenatal dietary education and supplementation to increase energy and protein intake. Cochrane Database of Systematic Reviews 20156 CD000032. (https://doi.org/10.1002/14651858.CD000032.pub3)
58 Rush D, Stein Z \& Susser M. A randomized controlled trial of prenatal nutritional supplementation in New York City. Pediatrics 198065 683-697.

59 Liberato SC, Singh G \& Mulholland K. Effects of protein energy supplementation during pregnancy on fetal growth: a review of the literature focusing on contextual factors. Food and Nutrition Research 2013 57. (https://doi.org/10.3402/fnr.v57i0.20499)

60 D'Amour P. Circulating PTH molecular forms: what we know and what we don't. Kidney International Supplements $2006 \mathbf{1 0 2}$ S29-S33. (https://doi.org/10.1038/sj.ki.5001599)

Received in final form 5 February 2021

Accepted 23 February 2021

Accepted Manuscript published online 26 February 2021

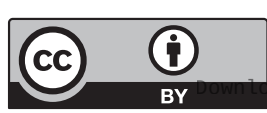

This work is licensed under a Creative Commons Attribution 4.0 International License.

ded from Bioscientifica.com at 04/26/2023 07:15:27AM 